\title{
GESTÃO DA CONTABILIDADE GERENCIAL: UM ESTUDO DE CASO EM UMA EMPRESA COMERCIAL NO MUNICIÍPIO DE ANANINDEUA NO PARÁ
}

\section{MANAGEMENT ACCOUNTING MANAGEMENT: A CASE STUDY IN A COMMERCIAL COMPANY IN THE CITY OF ANANINDEUA IN PARÁ}

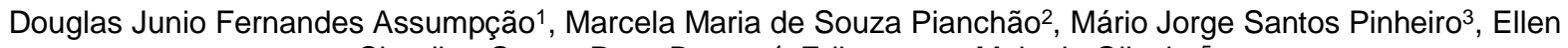
Claudine Castro Paes Barreto ${ }^{4}$, Ediemerson Melo de Oliveira ${ }^{5}$

\author{
Submetido: 16/02/2021 \\ Aprovado: 12/03/2021
}

\section{RESUMO}

O presente artigo apresenta como objeto de pesquisa as informações utilizadas pela contabilidade gerencial que contribuem como procedimentos de gestão para uma empresa comercial, no qual foi realizada uma análise bibliográfica sob a ótica contábil. Nesse contexto, o objetivo geral deste artigo é identificar quais são as informações aplicadas por uma contabilidade controlada, que possam contribuir no processo de gestão orientada em uma empresa, com o propósito de responder aos seguintes objetivos específicos: analisar como são tomadas as decisões para o gerenciamento empresarial; examinar quais as ferramentas possíveis a serem utilizadas e, desenvolver referências dos benefícios obtidos ao longo de uma contabilidade gerencial. A pesquisa qualifica-se como explicativa e descritiva. Os dados foram obtidos através de pesquisas bibliográficas, com abordagens de análises quantitativas e qualitativas. Os resultados encontrados indicam que a gestão da empresa possibilitou uma relevante transformação no papel desempenhado pelos contadores nas tomadas de decisões.

PALAVRAS-CHAVE: Contabilidade Gerencial. Tomadas de decisões. Gestão Empresarial.

\begin{abstract}
This article presents as research object the information used by management accounting that contribute as management procedures for a commercial company, in which a bibliographic analysis was carried out from an accounting perspective. In this context, the general objective of this article is to identify what information is applied by controlled accounting, which can contribute to the management process oriented in a company, in order to answer the following specific objectives: to analyze how decisions are made for the business management; to examine which tools are possible
\end{abstract}

\footnotetext{
1 Pós-doutorando em Industria Criativa pela Universidade Feevale FEEVALE). Doutor em Comunicação e Linguagens pela Universidade Tuiuti do Paraná (UTP). Vice-Líder do Grupo de Pesquisa (GP) Estudos de Capital Social e Cultural (UNAMA/CNPq); Professor da Escola Superior Madre Celeste (ESMAC) e do Programa de Pós-graduação em Comunicação, Linguagens e Cultura (PPGCLC) da Universidade da Amazônia (UNAMA) - http://orcid.org/0000-0001-5048-6692 - rp.douglas@hotmail.com

2 Mestra em Gestão de Empresas pela Universidade Lusófona de Humanidades e Tecnologias (ULHT) Lisboa/Pt com revalidação de diploma realizado pela Universidade Federal do Rio de Janeiro - UFRJ; Tutora de Formação a Distância; Docente de graduação e pós-graduação na Escola Superior Madre Celeste(ESMAC) http://orcid.org/0000-0002-5341-2434 - marcelapianchao@yahoo.com.br

3 Mestre em Administração pela Faculdade de Estudos Administrativos de Minas Gerais (FEAD); Mestre em Planejamento pela Universidade Federal do Pará (UFPA); Coordenador de Curso bacharelado em Administração e Ciências Contábeis da Escola Superior Madre Celeste (ESMAC). - http://orcid.org/0000-00027818-5231 - profmariojspinheiro@outlook.com

4 Doutoranda do Programa de Pós-graduação em Ciências Economia pela Universidade Federal do Pará (UFPA). Mestra em Engenharia Mineral pela Universidade Federal de Ouro Preto (UFOP). Professora da graduação e pós-graduação da Escola Superior Madre Celeste (ESMAC). - http://orcid.org/0000-0001-50199028 - ellen_claudine@hotmail.com

5 Bacharel em Ciências Contábeis pela Escola Superior Madre Celeste (ESMAC) - http://orcid.org/0000-00034023-7670 - contediemerson@gmail.com
} 


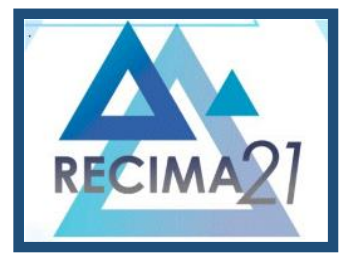

\section{RECIMA21 - REVISTA CIENTÍFICA MULTIDISCIPLINAR}

GESTÃO DA CONTABILIDADE GERENCIAL: UM ESTUDO DE CASO EM UMA EMPRESA COMERCIAL NO MUNICÍPIO DE ANANINDEUA NO PARÁ Douglas Junio Fernandes Assumpção, Marcela Maria de Souza Pianchão, Mário Jorge Santos Pinheiro, Ellen Claudine Castro Paes Barreto, Ediemerson Melo de Oliveira

to be used and to develop references of the benefits obtained during management accounting. The research qualifies as explanatory and descriptive. The data were obtained through bibliographic research, with quantitative and qualitative analysis approaches. The results found indicate that the company's management enabled a relevant transformation in the role played by accountants in decision making.

KEYWORDS: Management accounting. Decision making. Business management.

\section{INTRODUÇÃO}

O ser empreendedor, em especial no setor brasileiro, apresentou uma forte tendência de mercado ano de 2020. Segunda a Global Entrepreneurshio Monitor (GEM) ${ }^{1}$ o Brasil é $4^{\circ}$ pais a liderar em atividades empreendedoras de cunho inovador, com a proposta de driblar a crise econômica.

A inserção de novos serviços e/ou produtos, originados de atividades empreendedoras, buscam uma consolidação no mercado e outros, já existentes, com a perspectiva mante o empreendimento.

Por outro lado, os mercados são complexos - refletindo, vale dizer, a própria complexidade das relações humanas estabelecidas entre estado e sociedade e o próprio mercado. A contabilidade se insere nesta linha e se apresenta, igualmente, como uma ciência complexa e igualmente útil e determinante para o desenvolvimento da sociedade e do mercado

Porem a visão, de alguns empreendedores, está centrada em vender o produto e esquecem que uma organização para que tenho um funcionamento pleno deve possuir estruturas departamentais ou serviços que auxiliem no desenvolvimento comercial frente ao mercado. $O$ departamento marketing, logística, departamento pessoal, departamento contábeis e outros são apenas elementos iniciais para o aprimoramento organizacional.

Assim as informações úteis providas, por cada setor, em especial pelo setor de contabilidade irão fornecer aos gestores das organizações dados que podem auxiliar processo decisório.

As informações úteis providas pela contabilidade gerencial subsidiam aos gestores das organizações no processo decisório. Os objetivos dessa contabilidade de fornecer, prover, mensurar, mensurar e repor informações dá apoio às necessidades dos gestores dentro da organização. (LIMA, 2019).

A contabilidade gerencial se preocupa com o fornecimento de informações aos administradores e aos gestores que dirigem e controlam suas operações. Ela fornece dados essenciais e necessários para gerir uma organização. Diante do exposto formulou-se a seguinte questão de pesquisa: Quais são as informações utilizadas pela contabilidade gerencial que

\footnotetext{
${ }^{1} O$ programa de pesquisa Global Entrepreneurship Monitor (GEM), de abrangência mundial, é uma avaliação anual do nível nacional da atividade empreendedora
} 


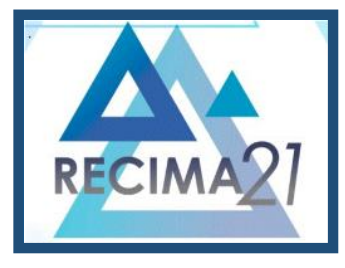

\section{RECIMA21 - REVISTA CIENTÍFICA MULTIDISCIPLINAR}

GESTÃO DA CONTABILIDADE GERENCIAL: UM ESTUDO DE CASO EM UMA EMPRESA COMERCIAL NO MUNICÍPIO DE ANANINDEUA NO PARÁ Douglas Junio Fernandes Assumpção, Marcela Maria de Souza Pianchão, Mário Jorge Santos Pinheiro, Ellen Claudine Castro Paes Barreto, Ediemerson Melo de Oliveira

contribuem no processo de análise e gestão em uma empresa comercial no município de Ananindeua-PA?

Para responder a indagação da pesquisa estabeleceu-se o objetivo geral de identificar quais são as informações utilizadas pela contabilidade gerencial que podem contribuir no processo de análise e gestão empresarial dentro de uma empresa comercial, assim sendo, auxiliando no processo de tomada de decisão.

Os objetivos específicos visam em compreender como são tomadas as decisões para o gerenciamento empresarial; examinar quais as ferramentas que são possíveis ser utilizadas; e, desenvolver referências dos benefícios de se obter uma contabilidade gerencial.

Para compreender mecanismo, da contabilidade gerencial na organização, realizou-se um estudo de caso em uma empresa comercial no setor de Ferro, Aço e Materiais de construção em geral, localizada no município de Ananindeua/PA. Trata-se de um estudo exploratório qual optou-se por uma pesquisa quali-quantitava tendo como ferramentas questionário e entrevista junto aos colaboradores do setor contábeis da organização. Afim de manter os princípios éticos da pesquisa, assim como a integridade da organização, neste trabalho, não será identificado o nome da organização em estudo.

Esta pesquisa justifica-se pela perspectiva de análise e gestão da contabilidade gerencial como auxílio para o processo de tomada de decisão dos gestores sob os pilares da eficiência, eficácia e economicidade, e sobre tudo, de como prevenir os possíveis erros.

Nesse contexto, o objetivo geral deste artigo é identificar quais são as informações utilizadas pela contabilidade gerencial que possam contribuir no processo e análise de uma gestão empresarial, o que auxilia no processo de tomada de decisão. Assim, fazem-se necessários os seguintes objetivos específicos: analisar como são tomadas as decisões para o gerenciamento empresarial; examinar quais as ferramentas que são possíveis de serem utilizadas; e, demonstrar os benefícios de se utilizar uma contabilidade gerencial.

Tendo como hipótese de que as informações oriundas da contabilidade gerencial, uma vez que são coerentes torna-se um instrumento para área contábeis e dos custos da organização, que são capazes influenciar, positivamente, as decisões e controles da empresa.

\section{FERRAMENTA E ESTRUTURA DA CONTABILIDADE GERENCIAL}

A contabilidade tem como objetivo fornecer informações que auxiliem na tomada de decisão, sendo esse o objetivo maior da ciência contábil, facilitar o planejamento, controle, avaliação de desempenho e tomada de decisão. Embora outros conceitos tenham sido colocados através da 


\section{RECIMA21 - REVISTA CIENTÍFICA MULTIDISCIPLINAR}

GESTÃO DA CONTABILIDADE GERENCIAL: UM ESTUDO DE CASO EM UMA EMPRESA COMERCIAL NO MUNICÍPIO DE ANANINDEUA NO PARÁ Douglas Junio Fernandes Assumpção, Marcela Maria de Souza Pianchão, Mário Jorge Santos Pinheiro, Ellen Claudine Castro Paes Barreto, Ediemerson Melo de Oliveira

história da administração, a organização depende de um assessoramento com informações de controle contábil-financeiro para a tomada de decisão. (MORAIS; JÚNIOR, 2019).

A contabilidade gerencial auxilia os empresários nas tomadas de decisões, a fim de controlar, planejar e corrigir as falhas da empresa, proporcionando um melhor gerenciamento. $\mathrm{Na}$ tabela 01 , pode-se observar que ela congrega elementos que complementam a contabilidade financeira, caracterizando-se como um enfoque especial, contribuindo com técnicas e procedimentos contábeis conhecidos e tratados na contabilidade financeira, na contabilidade de custos, na análise financeira, de balanços e outras ferramentas. (MORAIS; JúNIOR, 2019).

Tabela 1: Visão Geral das Características Básicas que compõem a Contabilidade Gerencial.

\begin{tabular}{|l|l|}
\hline \multicolumn{1}{|c|}{ TÓPICOS } & \multicolumn{1}{c|}{ CARACTERISTICAS DA CONTABILIDADE GERENCIAL } \\
\hline Público-alvo & Interno: Funcionários, gerentes e executivos. \\
\hline Objetivo & $\begin{array}{l}\text { Informar para tomada de decisões internas feitas por empregados, } \\
\text { gestores e executivos: feedback e controle do desempenho das } \\
\text { operações. }\end{array}$ \\
\hline Temporalidade & Corrente; orientada para o futuro. \\
\hline Restrições & $\begin{array}{l}\text { Sem regras estabelecidas: sistemas e informações determinadas por } \\
\text { gerentes para encontro de necessidades estratégicas e operacionais. }\end{array}$ \\
\hline Tipo de Informação & $\begin{array}{l}\text { Financeiras mais medidas operacionais e físicas sobre processos, } \\
\text { tecnologias, fornecedores, clientes e competidores. }\end{array}$ \\
\hline Natureza da Informação & Mais subjetiva e de juízos; válidas, relevantes, acuradas. \\
\hline Escopo & Desagregado, de informação às ações e decisões locais. \\
\hline Fon
\end{tabular}

Fonte: Atkinson (2015). Adaptado pelo autor (2020).

Elaborar planos administrativos e instrumentos de apoio às funções, focando a avaliação de resultados. Auxiliar no gerenciamento de departamento, enxergar e corrigir problemas, ajudar a empresa a crescer e gerar lucros e diminuir a taxa de mortalidade empresarial e o desemprego. A contabilidade gerencial é excelente ferramenta que dá suporte â administração financeira, de forma exclusiva, fornecendo instrumentos administrativos para auxiliar gerentes. (MORAIS; JÚNIOR, 2019).

\subsection{GESTÃO FINANCEIRA}

A Gestão Financeira é o ramo da administração que responsabiliza os recursos financeiros da empresa, tendo como objetivo o aumento do lucro, isto é, impulsionar o valor do mercado do capital de uma empresa (CHIAVENATO, 2014).

A contabilidade financeira, conforme a tabela 2, observa-se que se trata do procedimento de elaboração de demonstrativos financeiros para propósitos externos: pessoal externo à organização, como acionistas, credores e autoridades governamentais. Esse processo é muito influenciado por autoridades que estabelecem padrões, regulamentadores e fiscais, bem como por exigências de auditoria de contadores independentes. (ATKINSON, 2015).

Tabela 2: Características Básicas da Contabilidade Financeira e Gerencial. CARACTERISTICAS BASICAS DA CONTABILIDADE FINANCEIRA

\begin{tabular}{l|l} 
Clientela & Externa: Acionistas, credores, autoridades tributárias.
\end{tabular}




\section{RECIMA21 - REVISTA CIENTÍFICA MULTIDISCIPLINAR}

GESTÃO DA CONTABILIDADE GERENCIAL: UM ESTUDO DE CASO EM UMA EMPRESA COMERCIAL NO MUNICÍPIO DE ANANINDEUA NO PARÁ Douglas Junio Fernandes Assumpção, Marcela Maria de Souza Pianchão, Mário Jorge Santos Pinheiro, Ellen Claudine Castro Paes Barreto, Ediemerson Melo de Oliveira

\begin{tabular}{|l|l|}
\hline Propósito & $\begin{array}{l}\text { Reportar o desempenho passado às partes externas; contratos com } \\
\text { proprietários e credores. }\end{array}$ \\
\hline Data & Histórica, atrasada \\
\hline Restrições & $\begin{array}{l}\text { Regulamentada: dirigida por regras e princípios fundamentais da } \\
\text { contabilidade e por autoridades governamentais }\end{array}$ \\
\hline Tipo de Informação & Somente para mensuração financeira \\
\hline Natureza da Informação & Objetiva, auditável, confiável, consistente, precisa. \\
\hline Escopo & Muito agregada; reporta toda a empresa. \\
\hline
\end{tabular}

Fonte: Atkinson (2015).

Assim como, a contabilidade financeira provê dados para usuários externos (acionistas bancos e fornecedores). A geração de seus relatórios possui informações monetárias de natureza econômica, financeira e patrimonial. (MARION E RIBEIRO, 2015).

\subsection{APLICAÇÃO DAS FERRAMENTAS DA CONTABILIDADE GERENCIAL}

A contabilidade é a ciência que informa a teoria e prática de processos de cálculo e registro da movimentação financeira de uma firma ou empresa. A aplicação da contabilidade é fornecer os usuários demonstrativos financeiros, com informações que os ajudarão a tomar decisões. O objetivo básico dos demonstrativos financeiros é prover informação útil para a tomada de decisões econômicas. (IUDICÍBUS, 2015).

Dentro da organização, os gerentes precisam de ferramentas confiáveis que apoiem o gerenciamento da empresa; cálculos, projeções, planilhas, relatórios e outros demonstrativos que possibilitem comparar orçamentos, definir preços de produtos ou serviços. Essa informação contábil será extraída de dentro da Contabilidade Gerencial para aperfeiçoar a tomada de decisão. (CAVALCANTE; SILVA, 2018).

ludícibus (2015, p. 21) explica as características da contabilidade gerencial:

A Contabilidade gerencial pode ser caracterizada, superficialmente, como um enfoque especial conferido a várias técnicas e procedimentos contábeis já conhecidos e tratados na contabilidade financeira, na contabilidade de custos, na análise financeira, balanços etc. colocados em uma perspectiva diferente, num grau de detalhe mais analítico ou numa forma de apresentação e classificação diferenciada, de maneira a auxiliar os gerentes das entidades em seu processo decisório (IUDÍCIBUS, 2015 P. 21).

Incluso a uma perspectiva diferente, num grau mais planejado e analítico, a contabilidade gerencial contribui com os gerentes na tomada de decisão. Assim, salienta-se refletir sobre a utilização das demonstrações contábeis nas empresas, analisando o Balanço Patrimonial, a demonstração do resultado do exercício e a demonstração do fluxo de caixa de ferramentas da contabilidade gerencial. (MORAIS; JÚNIOR, 2019).

\subsection{ANÁLISE DAS DEMONSTRAÇÕES CONTÁBEIS}

ISSN: 2675-6218 - RECIMA21 - Ciências Exatas e da Terra, Sociais, da Saúde, Humanas e Engenharia/Tecnologia 


\section{RECIMA21 - REVISTA CIENTÍFICA MULTIDISCIPLINAR}

GESTÃO DA CONTABILIDADE GERENCIAL: UM ESTUDO DE CASO EM UMA EMPRESA COMERCIAL NO MUNICÍPIO DE ANANINDEUA NO PARÁ Douglas Junio Fernandes Assumpção, Marcela Maria de Souza Pianchão, Mário Jorge Santos Pinheiro, Ellen Claudine Castro Paes Barreto, Ediemerson Melo de Oliveira

A contabilidade gerencial possui instrumentos bastante úteis na hora de administrar uma empresa. Através dessas ferramentas gerenciais, os contadores elaboram um parecer aos gestores sobre como anda a atuação da organização. As empresas necessitam de informações confiáveis, no tempo certo e de forma objetiva que facilitem a tomada de decisão. Sob esse enfoque a contabilidade gerencial contribui para esse processo de tomada de decisão. (LIMA, 2019).

Elas são os indicadores que medem o quadro geral das empresas e eliminam os riscos de fracasso. Para ser usada como ferramenta na tomada de decisão, a contabilidade gerencial precisa ser integrada com a contabilidade de custos, contabilidade financeira e todos os dados contábeis. (CAVALCANTE; SILVA, 2018).

Salienta ressaltar que uma boa gestão de uma organização e a obtenção de lucro está sujeito a um plano financeiro com valores e metas bem estabelecidos. Para que este plano financeiro seja executado com excelência e rigor, o empresário contará com os recursos da contabilidade gerencial (CREPALDI, 2017).

São duas as demonstrações consideradas as mais importantes e mais utilizadas: O Balanço Patrimonial e a Demonstração do Resultado do Exercício (BAZZI, 2015).

\subsection{ANÁLISE DE CUSTOS PARA DECISÃO}

A apuração e o controle dos custos são relevantes para qualquer organização ao observar a figura 01, "pode-se visualizar o modelo do custeio variável imaginando a empresa como se fosse uma máquina. Para essa máquina funcionar no período considerado, é necessário cobrir os custos fixos, independentemente do que for produzido". (CREPALDI, 2017, p.115).

Figura 1: Custeio Variável.

\section{CUSTEIO VARIÁVEL}

Fonte: Custos (2020).

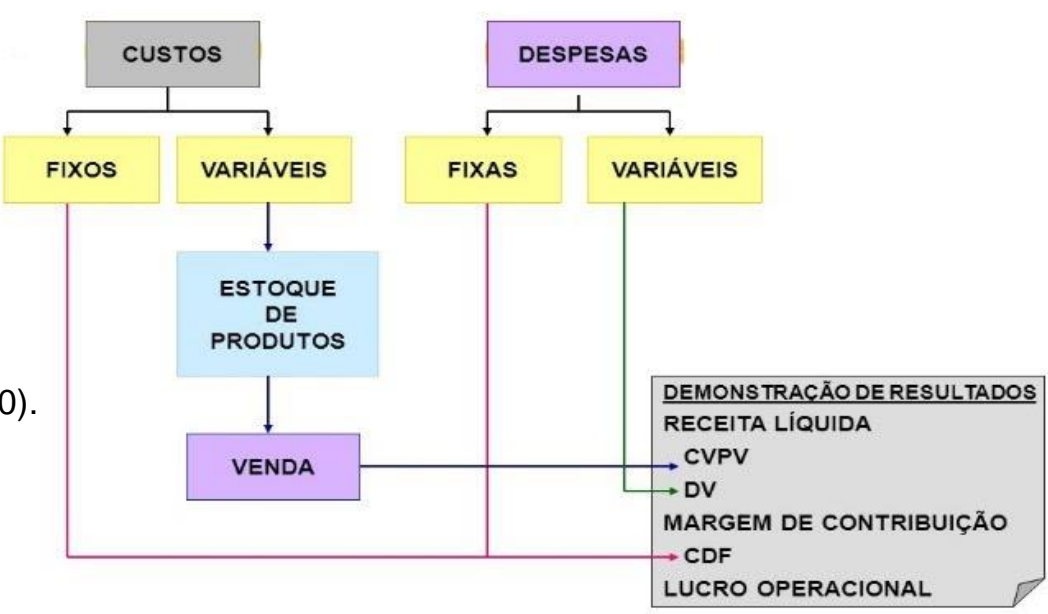




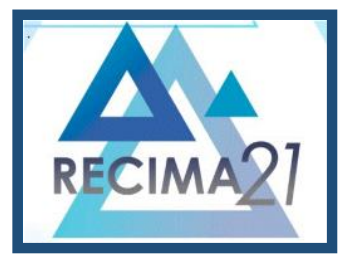

\title{
RECIMA21 - REVISTA CIENTÍFICA MULTIDISCIPLINAR
}

GESTÃO DA CONTABILIDADE GERENCIAL: UM ESTUDO DE CASO EM UMA EMPRESA COMERCIAL NO MUNICÍPIO DE ANANINDEUA NO PARÁ

Douglas Junio Fernandes Assumpção, Marcela Maria de Souza Pianchão, Mário Jorge Santos Pinheiro, Ellen Claudine Castro Paes Barreto, Ediemerson Melo de Oliveira

Exemplo: A empresa EX, em um determinado mês, produziu 80.000 unidades. Os custos totais do período atingiram $\$ 1.400 .000$, sendo $\$ 1.000 .000$ de custos fixos e $\$ 400.000$ de custos variáveis. Qual é o custo do produto de acordo com o custeio variável? Resposta: O custeio variável considera apenas $\$ 5,00(400.000 / 80.000)$ como sendo custos do produto. O restante $(\$ 1.000 .000)$ é custo do período (CAVALCANTE; SILVA, 2018).

Assim sendo, o sistema de custeio direto é útil para a tomada de decisões administrativas ligadas a fixação de preços, decisão de compra ou fabricação, determinação do mix de produtos e, ainda, para possibilitar a determinação imediata do comportamento dos lucros em face das oscilações de vendas (CREPALDI, 2017).

\begin{abstract}
Para o CPC 16, os estoques compreendem bens adquiridos e destinados à venda, incluindo, por exemplo, mercadorias compradas por varejista para revenda ou terrenos e outros imóveis para revenda. Os estoques também compreendem produtos acabados e produtos em processo de produção pela entidade e incluem matérias-primas e materiais, aguardando utilização no processo de produção e devem ser mensurados pelo valor de custo ou pelo valor realizável líquido, dos dois os menores, devendo incluir todos os custos de aquisição e de transformação, bem como outros custos incorridos para trazer os estoques à sua condição e localização atuais. (CPC 16).
\end{abstract}

O custeio por absorção, representado na figura 02, significa apropriação de Custos. Sendo um método desenvolvido a partir da aplicação dos conceitos básicos da contabilidade clássica e que consiste na apropriação de todos os custos de produção aos produtos produzidos, assim como todos os demais gastos relativos ao esforço aplicado na produção. (MARTINS, 2015).

Figura 2: Custeio por Absorção.

Fonte: Custos (2020).

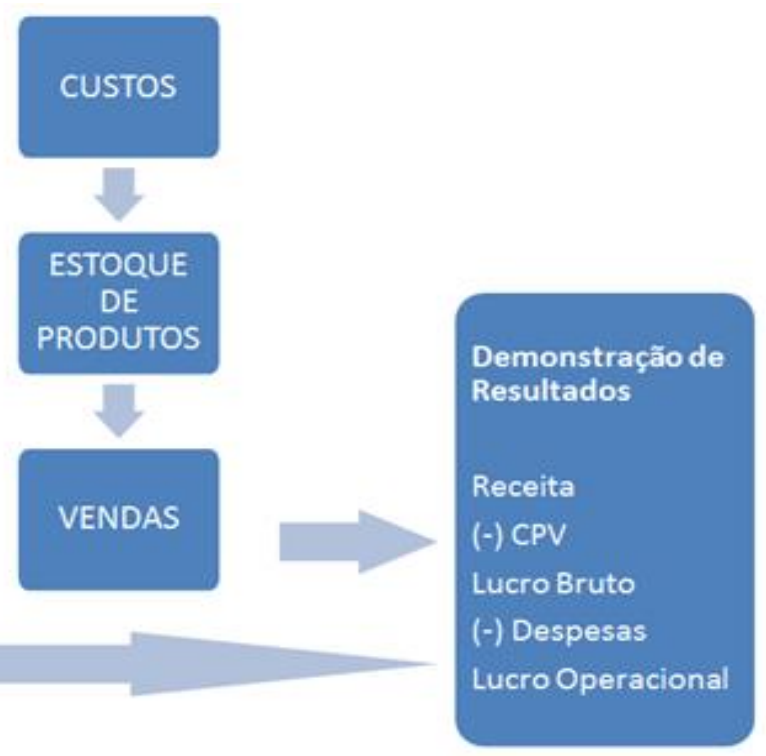




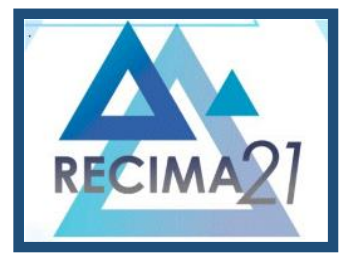

\section{RECIMA21 - REVISTA CIENTÍFICA MULTIDISCIPLINAR}

GESTÃO DA CONTABILIDADE GERENCIAL: UM ESTUDO DE CASO EM UMA EMPRESA COMERCIAL NO MUNICÍPIO DE ANANINDEUA NO PARÁ Douglas Junio Fernandes Assumpção, Marcela Maria de Souza Pianchão, Mário Jorge Santos Pinheiro, Ellen Claudine Castro Paes Barreto, Ediemerson Melo de Oliveira

Já a principal utilidade do custo padrão é funcionar como um instrumento de planejamento e controle de custos por unidade de produto; nesse sentido, ele deve ser integrado ao processo de planejamento operacional da empresa como um todo. (MARTINS, 2015).

$\mathrm{Na}$ execução das atividades, convém orientar as ações e decisões que são necessárias no dia a dia, por meio dele, os funcionários sabem, de antemão, a qualquer momento, qual deve ser a quantidade de material, o tempo de mão de obra, o tempo de máquina etc.; isso facilita a realização do trabalho. Ele é um instrumento de busca de melhorias contínuas. (MARTINS, 2015).

Com isso, no âmbito da contabilidade, o uso de custo padrão ajuda a agilizar o processo de fechamento e preparação dos relatórios mensais: pode-se apurar o valor dos estoques de produtos acabados e em processamento e o resultado do mês ao custo padrão, comparando-os com o real a períodos mais longos trimestralmente, por exemplo. (NASCIMENTO, 2015).

\subsection{BENEFÍCIOS DE SE OBTER UMA CONTABILIDADE GERENCIAL}

Uma empresa é uma organização de pessoas para a exploração de um negócio que produz ou oferece bens e serviços, com vistas, em geral, à aquisição de lucros. Ela pode ser particular, governamental ou de economia mista, além de poder ter diferentes formas jurídicas. (CAVALCANTE; SILVA, 2018).

Usam-se os termos contabilidade gerencial para se referir à atividade dentro da organização e contabilidade financeira quando a organização presta informações a terceiros. A contabilidade trata da coleta e apresentação e interpretação dos fatos econômicos. (CREPALDI, 2017).

Tabela 3: Vantagens da contabilidade gerencial. A CONTABILIDADE GERENCIAL PROPORCIONA AS SEGUINTES VANTAGENS:

1. Ajuda a aumentar a eficácia de todas as funções de gestão;

2. Melhora o controle financeiro da empresa;

3. Contribui para manter o foco do objetivo, tomada de decisão, a fixação de preços de produtos e serviços;

4. Evita excessos e desperdícios;

5. Colabora com a melhoria da comunicação entre todos os níveis de gestão;

6. Controla o custo de produção aumentando a porcentagem de lucro;

7. Auxilia na tomada de decisões estratégicas;

8. Orienta as estratégias do processo decisório;

9. Disponibiliza alternativas de redução de custos e despesas;

10. Provê a organização para que ela tenha vantagem competitiva e crescimento;

11. Fornece indicadores de desempenho do negócio;

12. Elaboração de relatórios que permitem fazer comparações projeções de orçamentos e outros.

Fonte: CAVALCANTE; SILVA, 2018. Adaptado pelos autores (2021). 


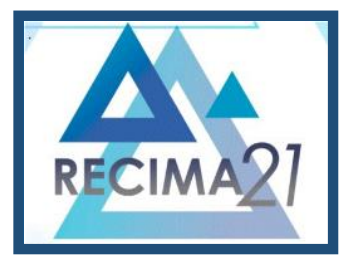

\section{RECIMA21 - REVISTA CIENTÍFICA MULTIDISCIPLINAR}

GESTÃO DA CONTABILIDADE GERENCIAL: UM ESTUDO DE CASO EM UMA EMPRESA COMERCIAL NO MUNICÍPIO DE ANANINDEUA NO PARÁ Douglas Junio Fernandes Assumpção, Marcela Maria de Souza Pianchão, Mário Jorge Santos Pinheiro, Ellen Claudine Castro Paes Barreto, Ediemerson Melo de Oliveira

A contabilidade gerencial tem a função suprir os administradores de empresas com ferramentas que os auxiliem em suas funções gerenciais, para melhorar o uso dos recursos econômicos da empresa, e adequar o controle dos insumos efetuado por um sistema de informação gerencial. Representa o conjunto das informações úteis para atender as necessidades da administração da empresa com o objetivo de auxiliar o processo decisório. (CAVALCANTE; SILVA, 2018).

\section{METODOLOGIA}

A pesquisa realizada é do tipo exploratória e descritiva, sendo aquela, segundo Gil (2010) com objetividade de fazer com que o pesquisador tenha uma proximidade com um assunto ainda pouco conhecido e pouco explorado; constitui o primeiro estágio de toda pesquisa científica, proporcionando uma maior identificação do pesquisador com problema, na qual se faz necessária a pesquisa bibliográfica ou entrevista do estudo de caso.

A técnica de coleta de dados adotada foi a bibliográfica e estudo de caso. Para Gil (2010, p.44), "a pesquisa bibliográfica é desenvolvida a partir de material já elaborado, e constituído principalmente de livros e artigos científicos". Ou seja, este tipo de pesquisa é a atividade que busca e consulta fontes diversas de informações publicadas referentes às informações utilizadas pela contabilidade gerencial

A abordagem adotada na pesquisa é do tipo qualitativa e quantitativa. A abordagem qualitativa utilizada na pesquisa foi o estudo de caso exploratório que busca "proporcionar maior familiaridade com o problema, com vistas a torná-lo mais explícito" (Gil, 2010, p.41).

$\mathrm{O}$ artigo utilizou questionários e entrevistas como instrumento de coleta de dados, da observação direta e análise de conteúdo. Lakatos e Marconi (2010) ressaltam que na entrevista a relação que se cria é de interação.

O estudo de caso centra-se em uma organização fundada em 2003, com forte atuação no segmento de Ferro, Aço e Materiais de Construção em geral. Atualmente contam com quatro unidades: Matriz em Ananindeua-PA, Filial-Jurunas em Belém-PA, Filial Castanhal/PA e Filial Abaetetuba/PA. Para desenvolvimento do trabalho optou-se unidade Matriz da organização, por ser a unidade principal, além de colaborar com o desenvolvimento regional de Ananindeua/PA.

A empresa é distribuidora das principais indústrias do Brasil com uma ampla linha de Aços planos e longos e um completo portfólio de produtos com estoque e pronta entrega para Construção Civil, Serralheria, Indústria e Agropecuária. O questionário foi aplicado no mês de setembro de 2020. Após definidas as repostas foi elaborado um banco de dados para mensurar as respostas. 


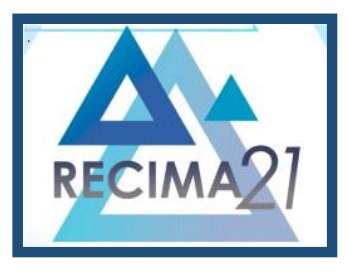

\section{RECIMA21 - REVISTA CIENTÍFICA MULTIDISCIPLINAR}

GESTÃO DA CONTABILIDADE GERENCIAL: UM ESTUDO DE CASO EM UMA EMPRESA COMERCIAL NO MUNICÍPIO DE ANANINDEUA NO PARÁ Douglas Junio Fernandes Assumpção, Marcela Maria de Souza Pianchão, Mário Jorge Santos Pinheiro, Ellen Claudine Castro Paes Barreto, Ediemerson Melo de Oliveira

O questionário foi aplicado, com 10 questões semiestruturadas, combinadas com entrevista, junto aos gerentes e coordenadores e assistentes da área contábeis. Totalizando 6, entrevistados da unidade matriz, no mês de novembro de 2020.

\section{DISCUSSÕES}

Durante da pesquisa pode-se observar que o recurso, de sistema de informação para manter seus controles internos, da organização, permite prover informações úteis no processo decisório, de planejamento e avaliação. Uma vez que as informações úteis providas pela contabilidade gerencial subsidiam aos gestores das organizações no processo decisório. (Merchant \& Otley, 2006).

Para, tanto, o software de controle gerencial utilizado pela organização é o Microsoft Office Excer, é realizado através de planilhas.

Afim de garantir o controle financeiro da organização, assim como dos recursos e uma boa gestão do patrimônio do negócio. A figura 03, representa o "Responsável Pelo Controle Financeiro da organização" observa-se que organização em estudo apontou que todos os setores, são divididos por cargos, existindo assim, divisão de tarefas. No caso do setor financeiro a divisão das funções está condicionada a: contabilidade, tesouraria, gestão das finanças, controle de tributos e gestão de custos.

Figura 3: Responsável Pelo Controle Financeiro da

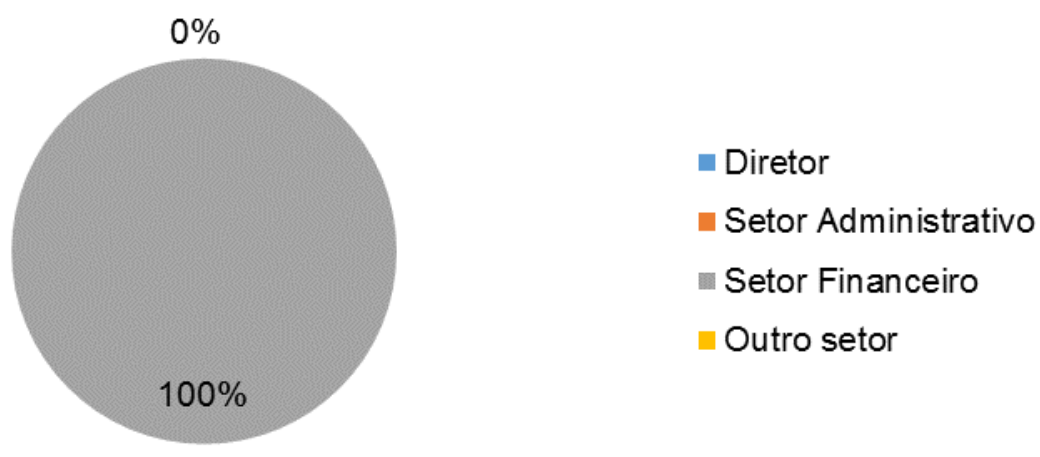

organização.

Fonte: O Autores (2021).

Pode-se observar, durante a pesquisa e, consequentemente, na entrevista junto aos gerentes que se torna fundamental a existência de um departamento de contabilidade, denominado

\footnotetext{
${ }^{2} \mathrm{O}$ Microsoft Excel é um editor de planilhas produzido pela Microsoft para computadores que utilizam o sistema operacional Microsoft Windowsm e computadores Macintos
} 


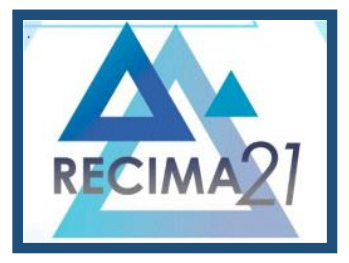

\section{RECIMA21 - REVISTA CIENTÍFICA MULTIDISCIPLINAR}

GESTÃO DA CONTABILIDADE GERENCIAL: UM ESTUDO DE CASO EM UMA EMPRESA COMERCIAL NO MUNICÍPIO DE ANANINDEUA NO PARÁ Douglas Junio Fernandes Assumpção, Marcela Maria de Souza Pianchão, Mário Jorge Santos Pinheiro, Ellen Claudine Castro Paes Barreto, Ediemerson Melo de Oliveira

Departamento Financeiro, que seja capaz de elaborar/levantar informações organizacionais que possibilitem a organização exercer um alto nível de aproveitamento dos dados gerados.

Incluso a uma perspectiva diferente, num grau mais planejado e analítico, a contabilidade gerencial contribui com os gerentes na tomada de decisão. Assim, salienta-se refletir sobre a utilização das demonstrações contábeis nas empresas, analisando o Balanço Patrimonial, a demonstração do resultado do exercício e a demonstração do fluxo de caixa de ferramentas da contabilidade gerencial. (MORAIS; JÚNIOR, 2019).

Todavia, ao relatar sobre a colaboração da contabilidade para o crescimento estratégico da empresa, a figura 04 abaixo apresenta que 100\% dos entrevistados acredita que a obtenção de lucro está sujeita a um plano financeiro com valores e metas estabelecidas e para tanto devem estar alinhados junto a estrutura contábil da organização para garantir o crescimento estratégico da organização.

Figura 04: Colaboração da Contabilidade Gerencial Para o Crescimento Estratégico da organização.

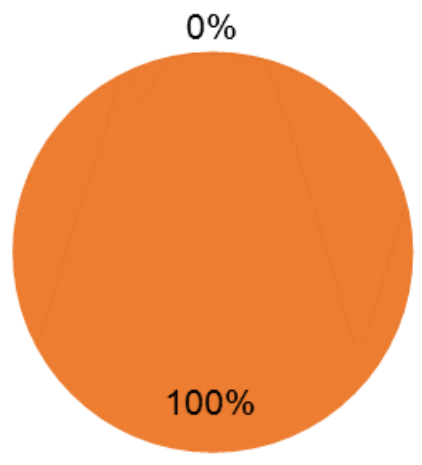

- Alta Colaborção

- Certa Colaboração

- Pouca Colaboração

Fonte: O Autores (2021) 


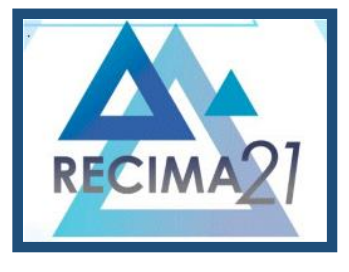

\title{
RECIMA21 - REVISTA CIENTÍFICA MULTIDISCIPLINAR
}

GESTÃO DA CONTABILIDADE GERENCIAL: UM ESTUDO DE CASO EM UMA EMPRESA COMERCIAL NO MUNICÍPIO DE ANANINDEUA NO PARÁ Douglas Junio Fernandes Assumpção, Marcela Maria de Souza Pianchão, Mário Jorge Santos Pinheiro, Ellen Claudine Castro Paes Barreto, Ediemerson Melo de Oliveira

Para que este plano financeiro seja executado com excelência e rigor, o empresário contará com os recursos da contabilidade gerencial (CREPALDI, 2017).

Ressaltou-se, também, quanto à colaboração do contador para o esclarecimento do negócio. E tem-se registrado de que a contabilidade financeira vem ser o procedimento de elaboração de demonstrativos financeiros para propósitos externos: pessoal externo à organização, como acionistas, credores e autoridades governamentais. Conforme a figura 05, nota-se um aproveitamento de todas as informações e dados elaborado pelo setor. Esse processo é muito influenciado por autoridades que estabelecem padrões, regulamentadores e fiscais, bem como por exigências de auditoria de contadores independentes (ATKINSON, 2015).

Figura 05 - O Aproveitamento da Contabilidade Gerencial no Processo de Tomada de Decisão da Empresa.

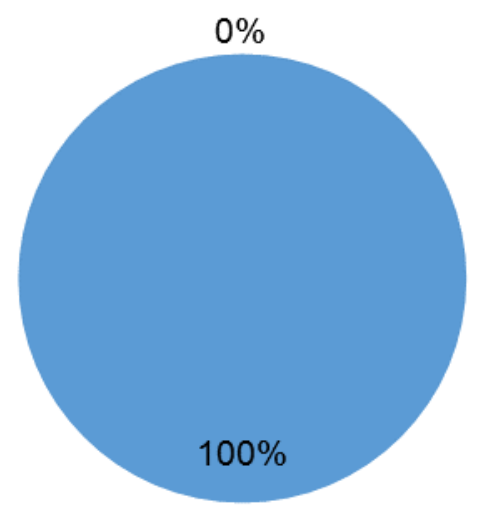

\author{
$\because$ Alto Nível de \\ Aproveitamento \\ - Certo Nível de \\ Aproveitamento \\ - Pouco Nível de \\ Aproveitamento
}

Fonte: O Autores (2020).

Tratando-se da relevância da utilização das ferramentas contábeis para melhor andamento do negócio, pode-se adentrar de que a contabilidade gerencial possui instrumentos bastante úteis na hora de administrar uma empresa. Através dessas ferramentas gerenciais, os contadores elaboram um parecer aos gestores sobre como anda a atuação da organização. As empresas necessitam de informações confiáveis, no tempo certo e de forma objetiva que facilitem a tomada de decisão. Sob esse enfoque a contabilidade gerencial contribui para esse processo de tomada de decisão. (LIMA, 2019).

Compreende-se desta forma, que organização em estudo obtém recursos e sistemas informacionais contábeis transparentes para com os gestores, afim de colaborar com 0 desenvolvimento e crescimento da organização.

\section{ENCAMINHAMENTOS FINAIS}

ISSN: 2675-6218 - RECIMA21 - Ciências Exatas e da Terra, Sociais, da Saúde, Humanas e Engenharia/Tecnologia 


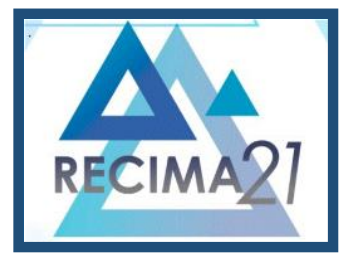

\section{RECIMA21 - REVISTA CIENTÍFICA MULTIDISCIPLINAR}

GESTÃO DA CONTABILIDADE GERENCIAL: UM ESTUDO DE CASO EM UMA EMPRESA COMERCIAL NO MUNICÍPIO DE ANANINDEUA NO PARÁ Douglas Junio Fernandes Assumpção, Marcela Maria de Souza Pianchão, Mário Jorge Santos Pinheiro, Ellen Claudine Castro Paes Barreto, Ediemerson Melo de Oliveira

O estudo tratou de focar um setor profundamente importante para a economia sobre análise e gestão da contabilidade gerencial: um estudo de caso em uma empresa comercial no município de Ananindeua no estado do Pará.

O ponto de partida foi à pergunta científica - quais são as informações utilizadas pela contabilidade gerencial que contribuem no processo de análise e gestão em uma empresa comercial no município de Ananindeua-PA? A partir desta inquietação, desta pergunta, realizou-se a pesquisa.

Em um primeiro momento, de fato, apresentou a consolidação de reflexões sobre as informações utilizadas pela contabilidade gerencial que podem contribuir no processo de análise e gestão empresarial dentro de uma empresa comercial, assim sendo, auxiliando no processo de tomada de decisão.

Com a utilização da contabilidade gerencial a empresa comercial cria um diferencial em relação à concorrência, dentre tantas ferramentas que existem na contabilidade gerencial, cada uma com uma finalidade, que irão depender dos resultados e interpretações corretas, além de comprovação, pois saber como foi registrado e como poderá ser útil. A questão da percepção dos setores de departamentalização contábil foi fundamental para o alcance do estudo e nisto vale a confirmação da hipótese implícita: de que contabilidade gerencial contribui no processo de análise e gestão da empresa, contribuindo para o processo de tomada de decisão, bem como uma grande oportunidade para se efetivar negócios além do plano local.

Sendo uma tarefa que exige tempo, mas poderá dizer para empresário quais decisões futuras poderá tomar para garantir a continuidade do seu negócio, e se seu investimento está de acordo com o planejamento estratégico. Recomenda que seja ainda estudada sobre a contribuição do contador, o qual pode evitar problemas com fiscalizações e autuações, e é ele quem pode trazer informações sobre o estado financeiro da empresa.

\section{REFERÊNCIAS}

ATKINSON, Anthony A. Contabilidade Gerencial. 4. ed. São Paulo: Atlas, 2015.

BAZZI, Samir. Contabilidade Gerencial: conceitos básicos e aplicação. Curitiba: Inter Saberes, 2015.

CAVALCANTE, Daiane Chaves. SILVA, Milton Neemias Martins. A Contabilidade Gerencial como Ferramenta de Gestão nas Organizações. Anápolis: Centro Universitário de Anápolis (Uni Evangélica), 2018. Disponível em: http://repositorio.aee.edu.br/. Acesso em: 11 set. 2020.

CHIAVENATO, Idalberto. Gestão financeira: uma abordagem introdutória. 3. ed. Barueri: Manole, 2014.

COMITÊ DE PRONUNCIAMENTOS CONTÁBEIS. CPC 26 (R1) - Apresentação das Demonstrações Contábeis. Disponível em: http://www.cpc.org.brl. Acesso em: 11 out. 2020. 


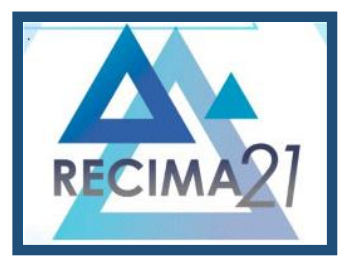

\section{RECIMA21 - REVISTA CIENTÍFICA MULTIDISCIPLINAR}

GESTÃO DA CONTABILIDADE GERENCIAL: UM ESTUDO DE CASO EM UMA EMPRESA COMERCIAL NO MUNICÍPIO DE ANANINDEUA NO PARÁ Douglas Junio Fernandes Assumpção, Marcela Maria de Souza Pianchão, Mário Jorge Santos Pinheiro, Ellen Claudine Castro Paes Barreto, Ediemerson Melo de Oliveira

CREPALDI, Silvio Aparecido. Contabilidade Gerencial: teoria e prática. 8. ed. São Paulo: Atlas, 2017.

CONTABILIDADE DE CUSTOS. Custeio Variável. 2020. Disponível em https://sites.google.com/site/contecustos/12---custo-padrão. Acesso em: 11 out. 2020

GIL, A. C. Métodos e técnicas de pesquisa social. 6. ed. São Paulo: Atlas, 2010.

IUDÍCIBUS, Sérgio de. Teoria da Contabilidade. 11. ed. São Paulo: Atlas, 2015.

LAKATOS, Eva Maria; MARCONI, M. Metodologia da Pesquisa. 8. ed. São Paulo: Atlas, 2010.

LIMA, Marco Aurélio Souza de. Contabilidade gerencial no processo de gestão empresarial: um estudo de caso em uma empresa comercial no município de Pão de Açúcar/AL. Universidade Federal de Alagoas em Santana de Ipanema: [S. e.], 2019. Disponível em: http://www.repositorio.ufal.br. Acesso em: 10 set. 2020.

MARION, José Carlos. Contabilidade Básica. 11. ed. São Paulo: Atlas, 2015.

MARION, José Carlos; RIBEIRO, Osni Moura. Introdução à contabilidade gerencial. São Paulo: Saraiva, 2014.

MARTINS, Eliseu. Métodos de Custeio Comparados: custos e margens analisados sob diferentes perspectivas. 2. ed. São Paulo: Atlas, 2015.

MORAIS, Rosa Amélia Carvalho; BARRETO JÚNIOR, Agenor Campos. A Importância da Contabilidade Gerencial para Microempresas e Empresa de Pequeno Porte. Id on Line Rev. Multidisciplinar e de Psicologia. v. 13, n. 43, p. 903-921, 2019. Disponível em: http://idonline.emnuvens.com.br/id. Acesso em: 10 set. 2020.

NASCIMENTO, Auster Moreira. Controladoria - Instrumento de apoio ao processo decisório. 2. ed. São Paulo: Atlas, 2015.

RIBEIRO, Osni Moura. Contabilidade de Custos. 4. ed. São Paulo: Saraiva, 2015.

VERGARA, Sylvia Constant. Projetos e Relatórios de Pesquisa em Administração. 14. ed. São Paulo: Atlas, 2013. 